\title{
Implementation of E-voting System for Student Union Government Elections
}

\author{
Aderibigbe I. Adekitan*, Victor O. Matthews, Temitope M. John, Stanley Uzairue \\ Department of Electrical and Information Engineering, Covenant University, Ota, Ogun State, Nigeria \\ ${ }^{*}$ Corresponding author, e-mail: ade_kitan@yahoo.com
}

\begin{abstract}
Several records of violence during student body elections in higher institutions of learning can be found dating back to the 1988 Abu crisis. The causal factors are multifaceted, involving both internal factors within the institution and external factors, and interest parties like main stream politicians. Suspicion of the possibility of rigging during a planned election can trigger pre-election violence, while alleged rigging during the election or the vote counting process is the major cause of election unrest during student government elections. The voting process is typically manual, and it is done through the use of ballot boxes and papers. This is error prone, inefficient and susceptible to rigging. Preventing mistrust-induced election violence requires the deployment of a trustworthy alternative to the paper ballot system. In this study, an electronic voting system is developed using Visual Basic and Microsoft Access Database. The application performs voter authentication by verifying a pre-issued pin which is unique for each voter. The system is accurate and engages the participation and login of agents who are representatives of the candidates' contesting for various offices thereby building trust in the process.
\end{abstract}

Keywords: electronic voting application, election security, student politics and violence, student union government, university voting system

Copyright $\odot 2018$ Universitas Ahmad Dahlan. All rights reserved.

\section{Introduction}

Student Union Government (SUG) is a central part of higher institution of learning, serving as an interface between the students and the management in the administration of the university. The SUG serves as a platform for the student community to express their views, communicate their desires and concerns to the university management, and also pursue common goals on a unitary platform [1]. The SUG prevents oppression of the student community by the management of the institution, and also articulates their views in cases of corruption and mismanagement of resources by the institution's management. The unified power of the university student body expressed through the SUG is often a major source of concern for most universities due to the SUG's power to drive the university to a standstill via protests, violence, media outcry and so forth. Hence, there is always an effort by the management of the institution to keep their activities under control, and to ensure that the SUG leadership is composed of the right individuals with the right visions to drive for success and greatness peaceably.

Student union politics and election into the SUG is quite partisan and this could be further intensified by various vested external interests. SUG politics is a microcosm of the national politics, and more often than not, the SUG is a tool for politicians to rally voters during national elections. This implies that a lot of funding and resources for campaign and spread of propaganda is made available to the SUG by some members of the university management, politicians and political parties [2], thereby creating political groups within the SUG, as student arm of many political parties [3]. This makes SUG electoral offices very juicy and attractive due to the benefits and opportunities that exist both in the present and after graduation, as a result of the links established with politicians and prominent individuals in the society, while in the institution through the SUG platform.

Student politics, campaign and voting can be very tense and divided along ethnic and religious lines, just like the national politics [2,4,5]. Several cases of SUG election violence has been recorded across the globe with a number of cases in Africa and Asia. This is often due to various forms of election malpractices and rigging [2]. In Nigeria, on March 10, 2015 student 
union election at the Yaba College of Technology turned violent after invasion by thugs during the election result counting process. Sporadic shots were fired and students had to flee the collation centre for their safety [6]. The post-election massacre of students at the Federal Polytechnic, Mubi [7] is another critical case of student election violence resulting in the loss of lives, leaving several others severely injured in its wake. Also, on the 24th of May, 2015, student union election went awry at the College of Education, Kangere, the resulting violence spilled from the institution to neighbouring communities with several innocent people injured as a result [8]. Meddling of external authorities in university student elections is not uncommon [9], this is usually geared at ensuring the victory of an anointed candidate, and such can easily trigger student revolt and violence; an example of this is the June 2016 protest and violence at the Ladoke Akintola University of Technology in Nigeria [10].

In India, on October 24, 2008 post-election violence erupted at Buxi Jagabandhu Bidyadhar College after student demanded for a vote recount due to alleged error [11]. A similar scenario played out at Utkal University on Sep 17, 2017 when an alleged attempt was made to scatter the already scheduled election by rival groups [12]. On September 28, 2015 at Allahabad University, series of pre-election violence erupted at the university. In 2017,

The setting of age limit for SUG voters by the $42^{\text {nd }}$ Senate of Tribhuvan University, Nepal triggered a wave of violence and protests [13], resulting in injuries and property destruction [13]. Students take different forms to express their displeasure with SUG election process and results, this could be through demonstrations, property destruction, arson and other forms of violence. Although, requirements for preventing SUG election violence are multifaceted, a major solution can be achieved by ensuring a smooth and malpractice free registration, voting and counting of election results. This can be deployed by designing and implementing an offline electronic voting system for the SUG elections as presented in this research work.

\section{Electronic Voting System}

Identified societal challenges are sometimes resolved by developing goal specific software applications to manage the issues. Voting is core to democratic processes and the mode of voting must be credible and trusted by all stakeholders [14]. An electronic voting system is a paperless form of voting system designed to prevent errors, manipulation, fraud and also ensure process integrity [15]. A good voting system must be tamper proof and also assure the anonymity of the voters for their protection and safety [16,17]. According to [18], one of the ways of securing e-voting system is by deploying them offline i.e. off the internet. This eliminates external risks and prevents hackers from accessing and manipulating the system. Evoting system provides a platform for fair voting process without undue pressure which empowers the voters to determine their leadership.

Electronic voting entails the use of computers or smart electronic devices for voting processes which eliminates the use of paper voting systems. Some e-voting systems are designed to produce paper trail of the voting process as a means of double checking and confirming manually the results of the electronic system. E-voting systems can be on or off the internet, internet based system creates opportunities for remote voting centres which increases accessibility and reduces queues at voting centres but it may be susceptible to identity fraud, hacking attacks and election result manipulation [19].

\section{The University Voting System Developed}

The Student Voting System (SVS) was developed using Microsoft Visual Basic in Visual Studio 2010 environment. The database on which the VB 2010 application runs was deployed using database programming with SQL Server and ADO.NET; a platform that provides a disconnected architecture allowing the system to scale up [20]. A Microsoft Access Database file is a relational database system that enables the linking of tables for improved database performance [21].

In a voting system, voter identification and authentication is very vital [22,23], this can be achieved by using a smart card [24], an online signature [25], a unique login details, pin and so forth. In the SVS developed, student data such as their complete names, matriculation number, Faculty, Department, academic level, emails and telephone numbers are obtained 
directly from the university MIS/ICT Centre. Using the names and the matric number of each student a unique access pin is generated for each student. The pin is generated and sent via mails and SMS to the students on the day of the election to prevent any form of manipulation and fraud. The SVS has three classes of users and access rights as detailed in Figure 1.

a. Administrators with full access to the database for adding voters and creating profiles for other SVS users as shown in Figure 9. The administrators login using the form shown in Figure 3 and manages the database as shown in Figure 8. The form for changing admin password is shown in Figure 5.

b. Agents-these are witnesses and appointed representatives of the contestants for the various SUG offices.

c. Voters-these are students of the institution that has been registered and approved to participate in the election.

The application is installed on computers at the voting centre with adequate arrangement to ensure secret ballot. Prior to the commencement of voting, the agents will login to confirm that the voting result for all the candidates is zero. Registered student voters will fill their details into the voter's login page and also enter the unique pin sent to them, and then click login. The system authenticates the data entered in Figure 2, and if confirm accurate, a message box is displayed showing the name and level of the student. The student must confirm his or her identity by clicking yes, in order to access the SUG candidates form for voting. If authentication fails the user is denied access and a warning message is displayed. To vote, the voter will select the corresponding checkbox for their preferred candidate and click NEXT to move to forms for candidates contesting for other positions as shown in Figure 7. On clicking NEXT, on the last candidates form, a VOTE confirmation dialog box is displayed, requesting the voter to confirm the desire to vote for the selected candidates. When the voter clicks VOTE, the database is updated for the selected candidates, and the application returns to the login page. The details of the voter, the pin used to vote and the time of voting is updated in a database table called "youhavevoted" This is to allow the system to check those who have voted so as to prevent double voting. The voting process is summarized in Figure 6.

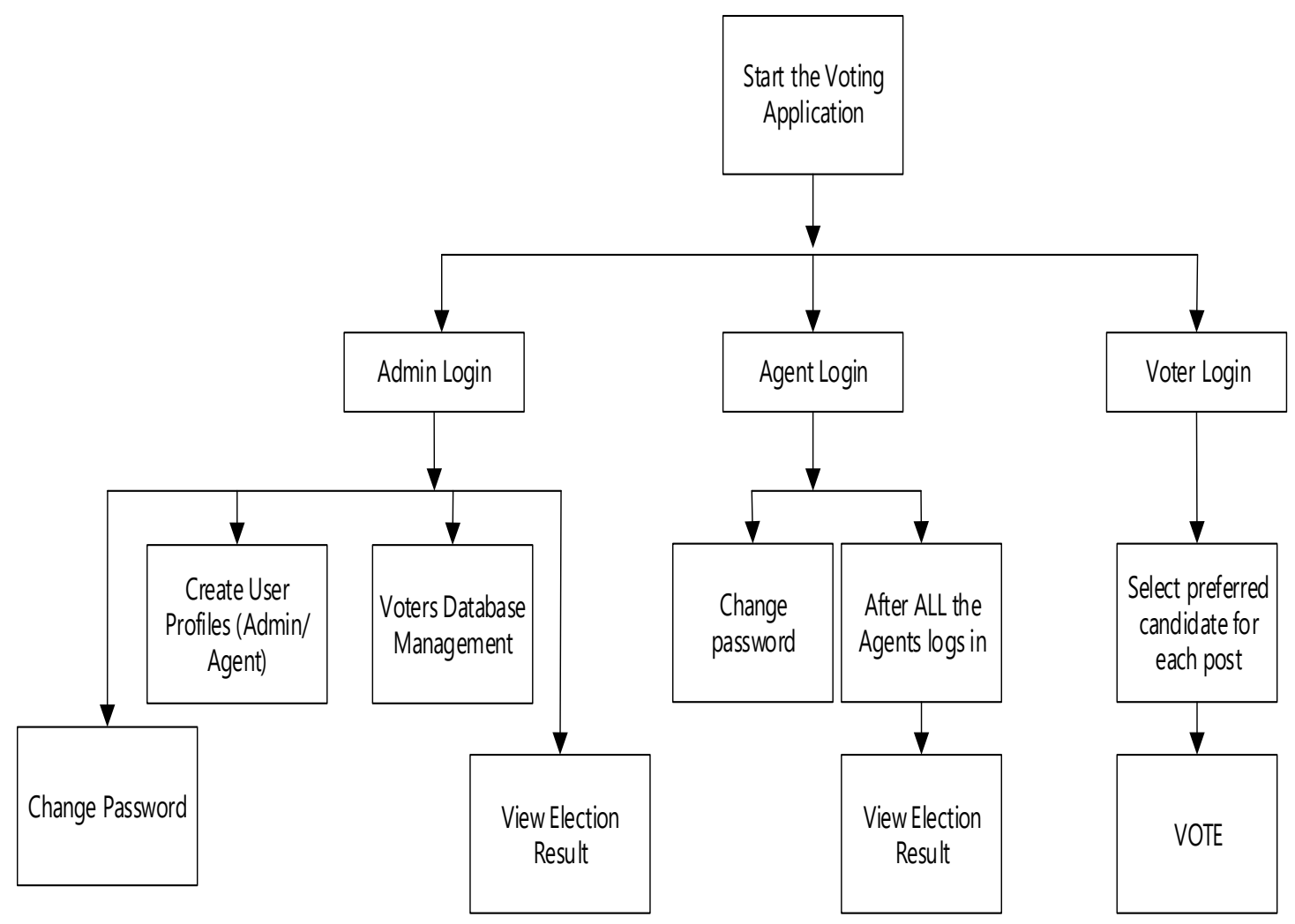

Figure 1. The access right of each class of SVS platform users 


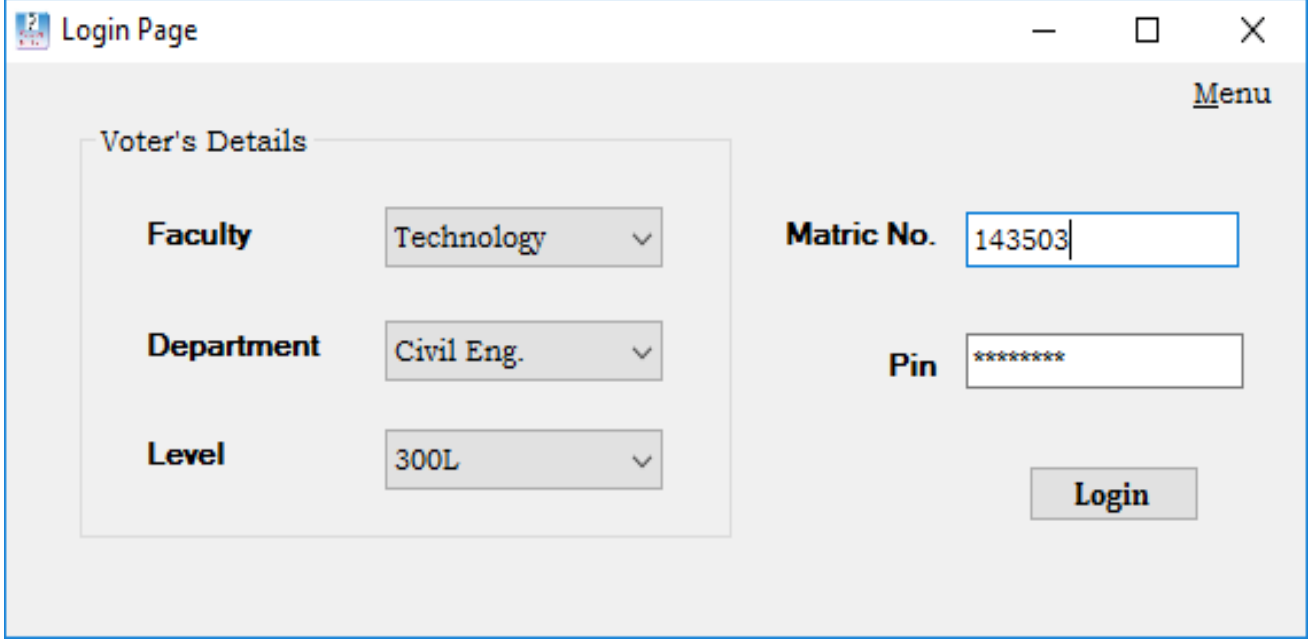

Figure 2. Voter's login form

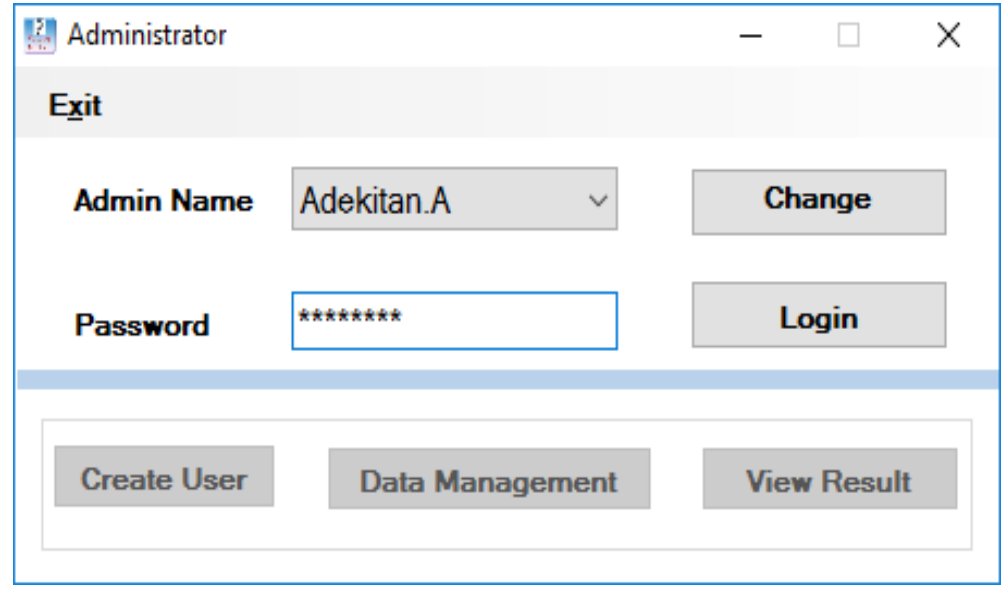

Figure 3. Admin login form

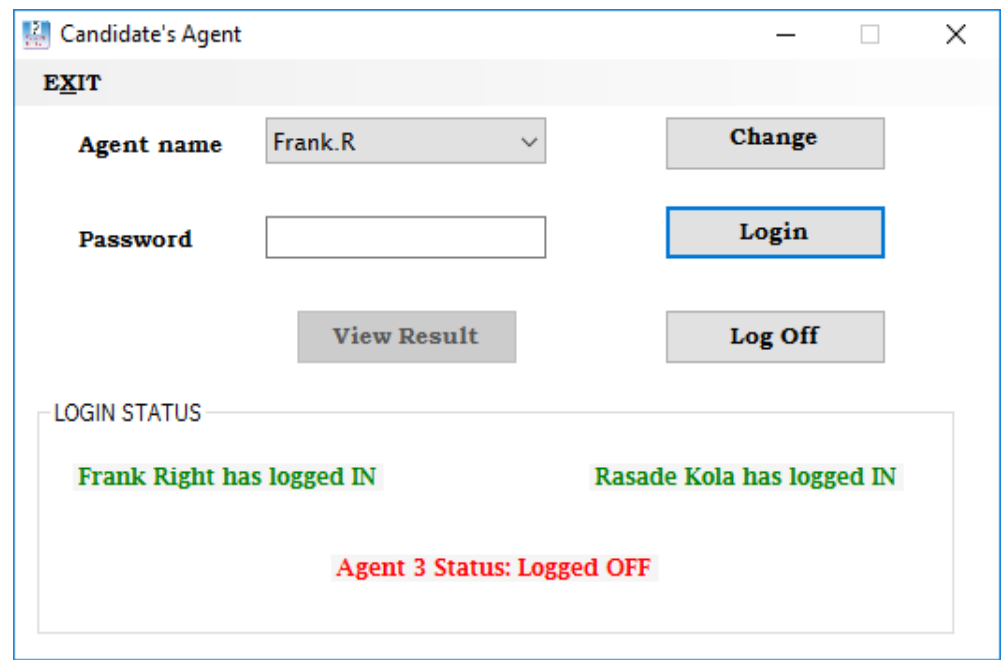

Figure 4. Agent's login form 


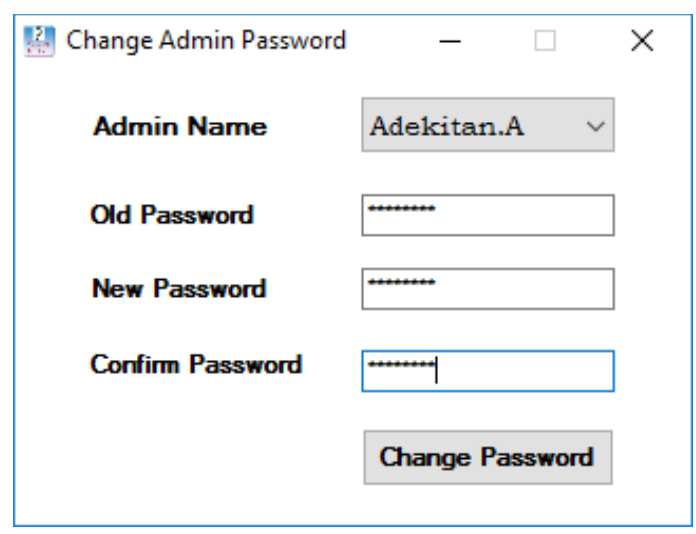

Figure 5. Password change form

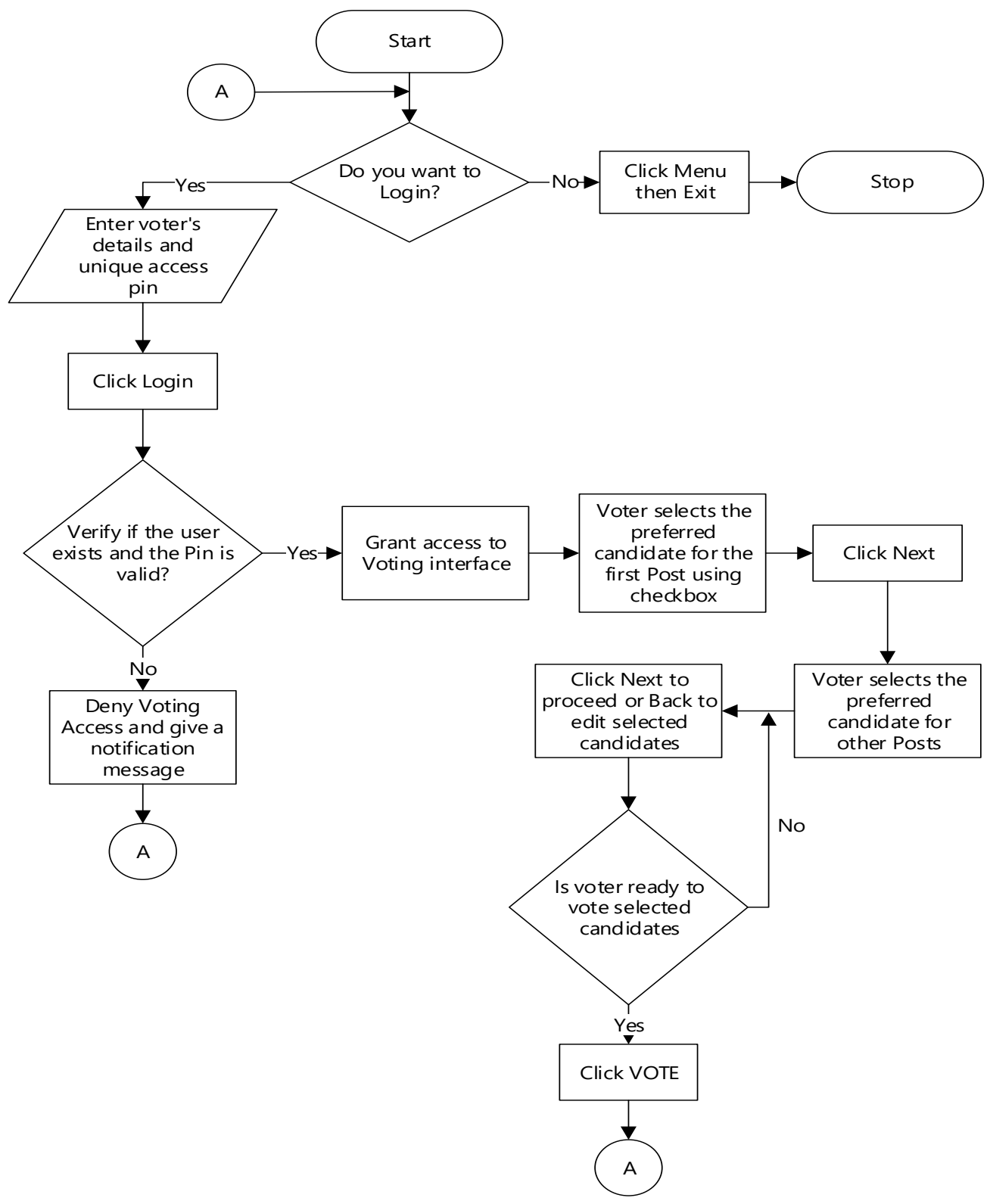

Figure 6. A flow chart of the voting process 


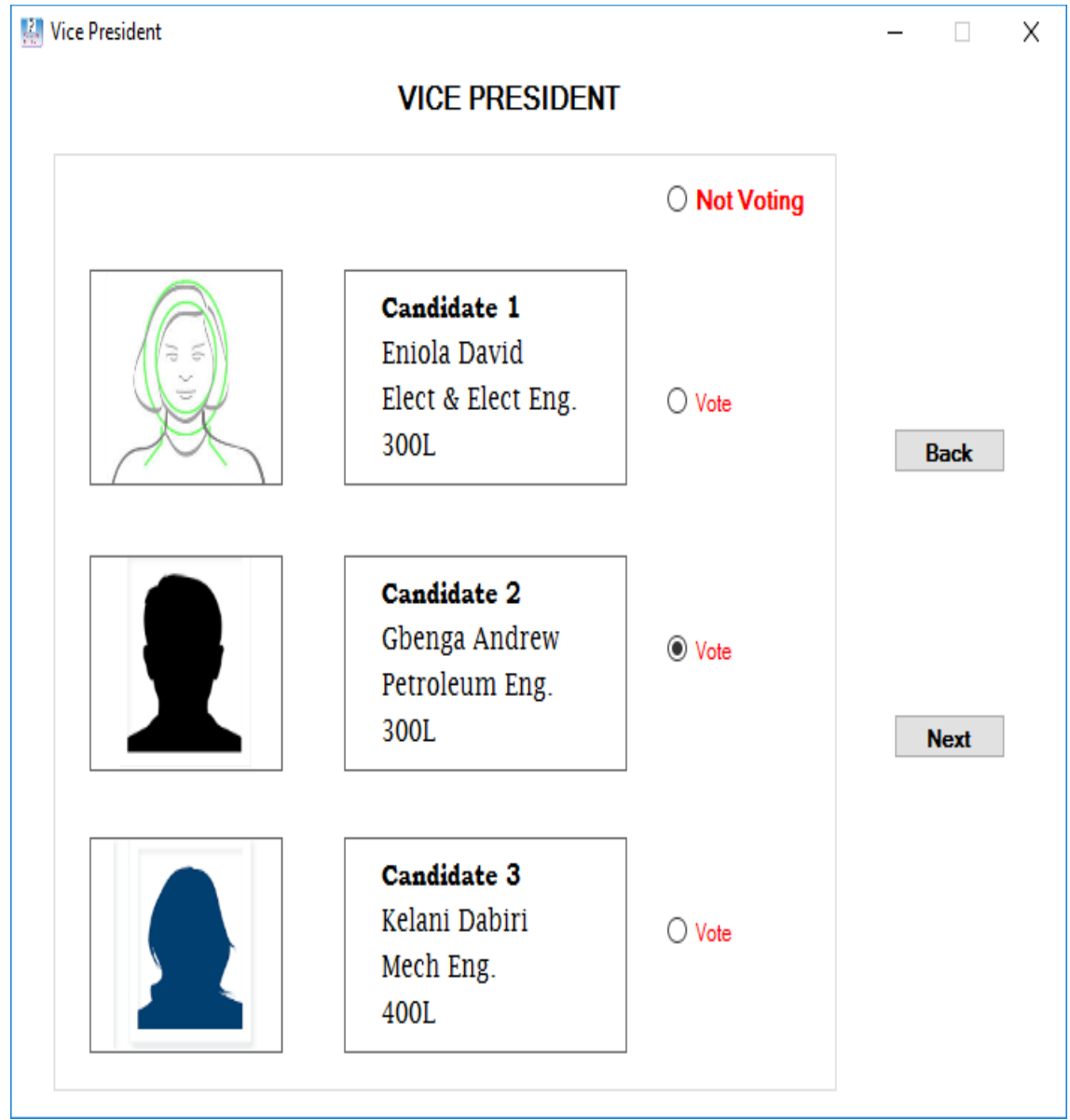

Figure 7. Candidates for the Vice President's Office

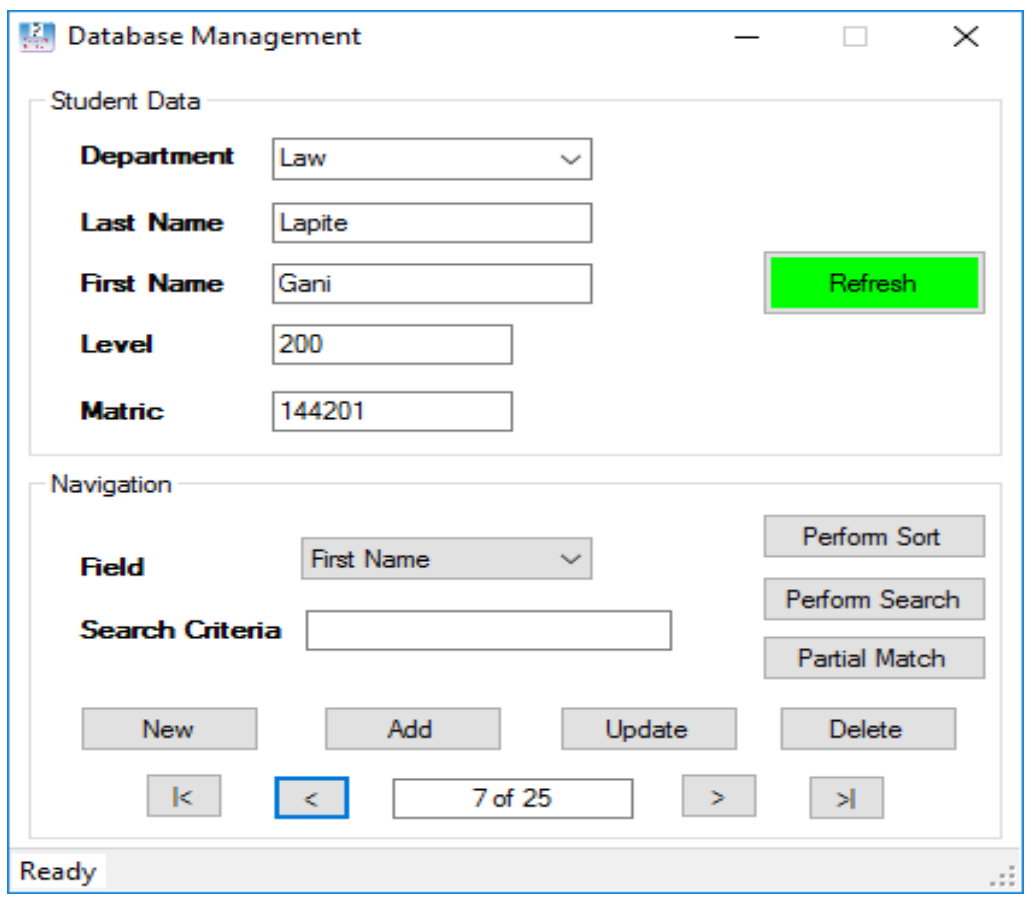

Figure 8. The Admin database management interface 
The system is programmed such that at the end of the voting exercise, each agent must login to the system one after the other and the view result button will remain inactive until ALL the agents have logged in. This is a confirmation of agents consent that the voting process is completed and all the agents are simultaneously present to view the result at the same time. This is shown in Figure 4 and Figure 10. The database structure is shown in Figure 11.

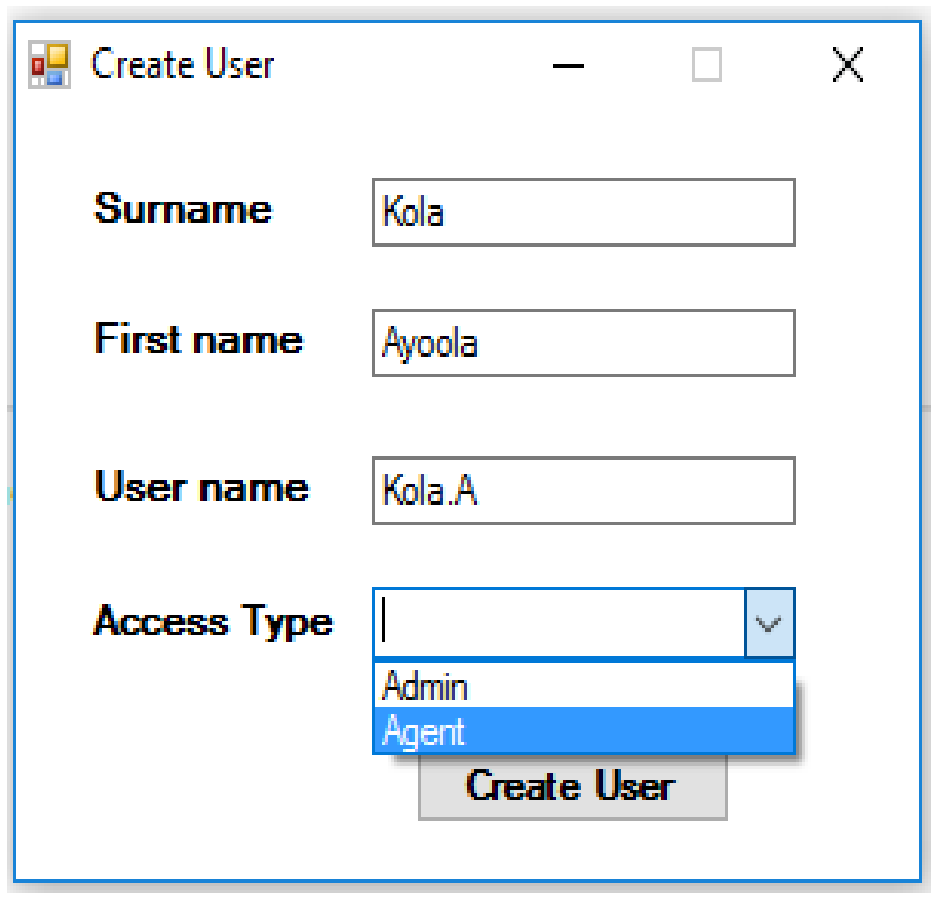

Figure 9. Form for creating Admin and Agent User Profile

\begin{tabular}{|c|c|c|c|c|c|}
\hline \multicolumn{4}{|c|}{ View Result } & \multirow{2}{*}{$\frac{\square}{\text { Votes }}$} & \multirow[t]{2}{*}{ X } \\
\hline & Post & First & Last & & \\
\hline & Finance Secretary & Stephen & Paul & 1456 & \\
\hline & Finance Secretary & James & Talabi & 671 & \\
\hline & Finance Secretary & Esther & Tolani & 350 & \\
\hline & Vice President & Gbenga & Andrew & 1350 & \\
\hline & Vice President & Kelani & Dabiri & 624 & \\
\hline & Vice President & Eniola & David & 528 & \\
\hline 米 & & & & & \\
\hline$<$ & & & & & $>$ \\
\hline
\end{tabular}

Figure 10. Election Result for two SUG posts 


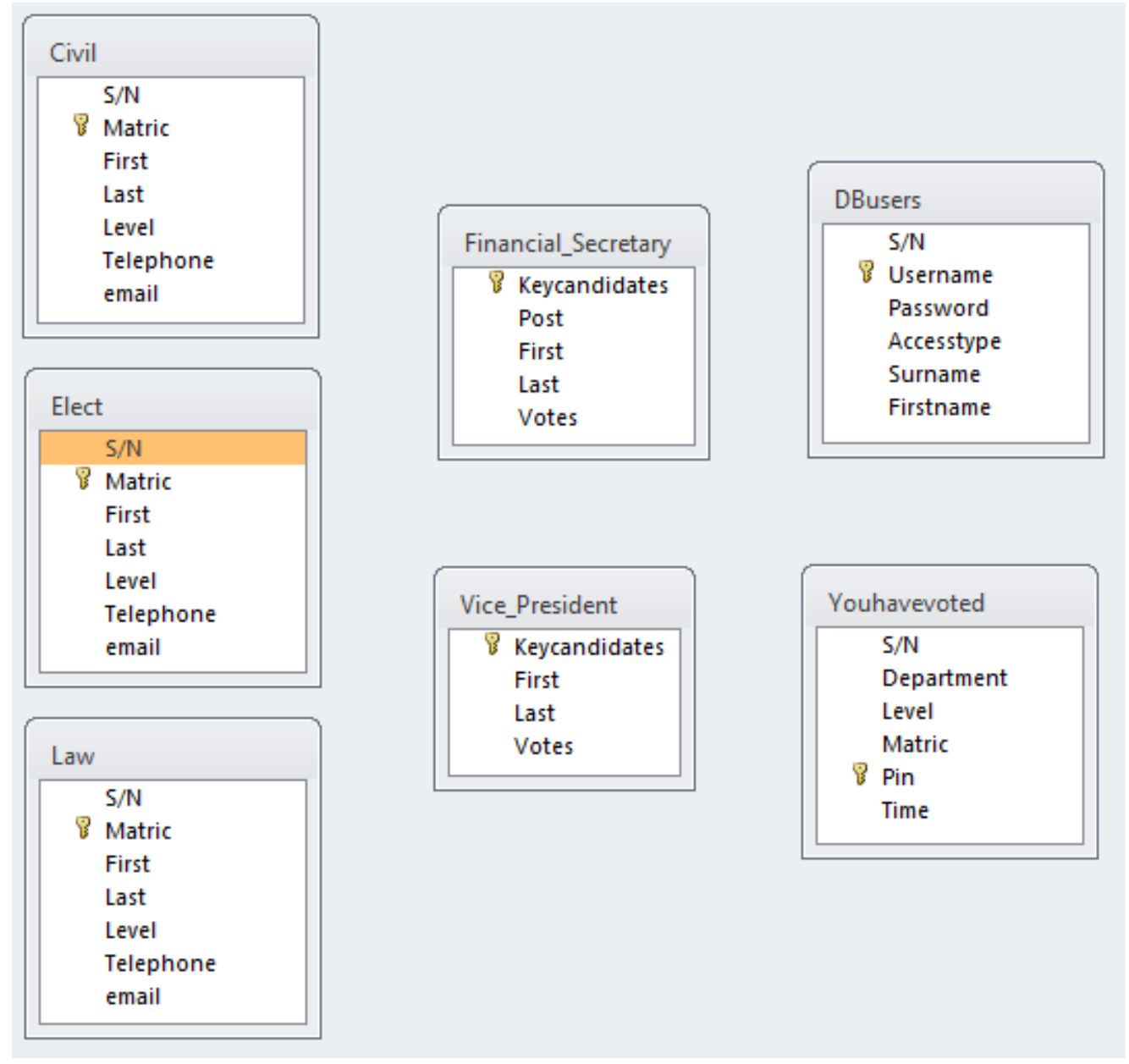

Figure 11. The database structure using three departments

\section{The benefits of the SVS}

The electronic SVS prevents fraud and election rigging by smuggling ballot paper into ballot boxes for paper based systems. It also prevents online hacking via the internet because it is deployed offline. The platform ensures the participation of all stakeholders which help to build trust and confidence in the SVS and the voting process. The paper backed, electronic voting system developed by [26] for the Austrian Federation of Students use a smart card which digitally identifies the voter, but in this study, Voter's authentication is via a unique access pin sent to the voters on the day of the election through SMS. The pin is free and does not require the cost of a unique smart card. The voting system implemented by the graduate student of the University of Ottawa requires electronic voter verification by a polling staff, while the actual voting is performed using a coded paper based ballot and clipboard system together with an optical scan, vote counting system [27], but in this study, the electronic SVS allows the user to personally login to the voting system, and the voting itself is done completely electronically.

In the voting system deployed by [27], user voting combinations is protected by shuffling the voting data, while for the SVS developed in this study, the voting system does not keep the record of the set of candidates voted for by any voter; it is programmed to only update the count for each candidate voted for and then discard the data, thereby providing anonymity [28] and protection for the voters.

\section{Conclusion}

Student body elections in higher institutions of learning have led to unrest and violence at various instances due to mistrust in the election process. An electronic voting system has 
been developed in this study for use in institutions for conducting Student Government Elections. The SVS eliminate the challenges of the paper based ballot system, and in particular, rigging during the voting and vote count process. The SVS is an offline system eliminating the opportunity for attack by hackers through the internet. The voting process engages all concerned stakeholders and interest groups via their representatives, thereby building trust in the voting process. The integrity and accuracy of the voting system eliminate the biases and doubts that typically accompanies Student Government elections which has resulted in violence in several academic institutions leading to injuries, loss of lives, destruction of properties and disruption to the core academic activities and calendar. The SVS is easy to use, efficient, accurate, secured, provides anonymity for voters, and it authenticates voters making it the preferred voting platform during SUG elections.

\section{Acknowledgement}

The Authors appreciate Covenant University Centre for Research, Innovation and Discovery for supporting the publication of this research.

\section{References}

[1] ZE Peter, ST Ebimobowei. Leadership and student unionism, challenges and solutions in the Nigerian tertiary education system (colleges of education, polytechnics and universities). European Scientific Journal (ESJ). 2015; 11.

[2] RD Uche, EO Odey. Leadership conflicts among students on Nigerian university campuses: the experience of the University of Calabar, Calabar-Nigeria. British Journal of Education. 2017; 5: 1-8.

[3] S Munshi. Student Politics: A Game-Theoretic Exploration. Indira Gandhi Institute of Development Research, Mumbai. 2014.

[4] OV Ojo. Turbulent election history: An appraisal of precipitating factors in Nigeria. International Journal of Politics and Good Governance. 2014; 5: 1-18.

[5] JO Fatile, KD Adejuwon. Conflict and conflict management in tertiary institutions: The case of Nigerian universities. European journal of humanities and social sciences. 2011; 7.

[6] S Reporters. Thugs, Violence Disrupt Student Exco Elections at YabaTech. 2015. Available: http://saharareporters.com/2015/03/10/thugs-violence-disrupt-student-exco-elections-yabatech

[7] S Reporters. Mubi Student Massacre: Killers Called Out Students' Names Before Shooting Them, Say Police. 2012. Available: http://saharareporters.com/2012/10/02/mubi-student-massacre-killerscalled-out-students\%E2\%80\%99-names-shooting-them-say-police

[8] I Ibrahim. Eight injured, 32 arrested as students' union election goes violent. Premium Times, ed. 2017.

[9] S Reporters. The 'audacity of madness' in the university of Calabar student union elections. 2009. Available: http://saharareporters.com/2009/11/27/\%E2\%80\%98audacity-madness\%E2\%80\%99university-calabar-student-union-elections

[10] O Alao. Violence mars LAUTECH Students' Union election. The Nation, ed. 2016.

[11] T Hindu. Violence mars student union polls. 2008. Available: http://www.thehindu.com/todayspaper/tp-national/tp-otherstates/Violence-mars-student-union-polls/article15328282.ece

[12] H Pradhan. Pre-poll violence: Section 144 clamped on Utkal University campus. The Times of India city, ed. 2017.

[13] N Monitor. Contestation and Violence Related to Free Student Union Election. 2017. Available: https://www.nepalmonitor.org/blog/2017/04/07/contestation-and-violence-related-to-free-studentunion-election/

[14] JP Nogueira, F de Sá-Soares. Trust in e-Voting Systems: A Case Study. Knowledge and Technologies in Innovative Information Systems. 2012: 51.

[15] G Neumann. Special Issue: The problems and potentials of voting systems. Communications of the ACM. 2004; 47.

[16] T Kohno, A Stubblefield, AD Rubin, DS Wallach. Analysis of an electronic voting system. Security and Privacy, 2004. Proceedings. 2004 IEEE Symposium on. 2004: 27-40.

[17] R Suwandi, SM Nasution, F Azmi. Secure E-voting system by utilizing homomorphic properties of the encryption algorithm. Telkomnika (Telecommunication Computing Electronics and Control). 2018; 16: 862-867.

[18] Brennan-Centre-for-Justice. Voting System Security and Reliability Risks. New York University School of Law. 2016

[19] T Habibu, K Sharif, S Nicholas. Design and Implementation of Electronic Voting System. International Journal of Computer \& organization Trends (IJCOT). 2017; 7: 1-6.

[20] T Willis, B Newsome. Beginning Visual Basic 2010. Wrox. 2010. 
[21] O Oni, O Oshin, O Oni, F Idachaba. Web-based Portal for Vehicle Licensing Management. Proceedings of the World Congress on Engineering London, U.K. 2015.

[22] SN John, CK Ayo, C Ndujuiba, CE Okereke. Design and Implemenation of a Unified e-ID Card for Secure e-Voting System (MUSES). International Journal of Computer and Information Technology. $2013 ; 2$.

[23] I Kabandana, ANN Kumar. FPF: Fraud Proof Framework for Electronic Voting System. 2016; 6.

[24] N Ya'acob, AM Azize, AL Yusof, SS Sarnin, NF Naim, SN Rohaizad. Web-based boarding school monitoring system. Indonesian Journal of Electrical Engineering and Computer Science. 2018; 11: 215-223.

[25] SA Daramola, MA Adefuminiyi, TM John. Online Signature for Attendance Verification System using Levenberg-Marquardt Neural Network. Proceedings of the World Congress on Engineering, London, U.K. 2016.

[26] R Krimmer, A Ehringfeld, M Traxl. The Use of E-Voting in the Austrian Federation of Students Elections 2009. Electronic voting. 2010; 167: 33-44.

[27] A Essex, J Clark, R Carback, S Popoveniuc. Punchscan in practice: An E2E election case study. Proceedings of Workshop on Trustworthy Elections. 2007.

[28] M Lubis, M Kartiwi, S Zulhuda. Privacy and personal data protection in electronic voting: Factors and measures. Telkomnika (Telecommunication Computing Electronics and Control). 2017; 15: 512-521. 